\title{
Whole-Brain Radiotherapy (WBRT) for Brain Metastases: Does the Interval Between Imaging and Treatment Matter?
}

\author{
HEINKE C. HANSEN ${ }^{1 *}$, STEFAN JANSSEN ${ }^{1,2^{*}}$, CATHRIN THIEME ${ }^{2}$, \\ ALEKSEJ PERLOV ${ }^{2}$, STEVEN E. SCHILD ${ }^{3}$ and DIRK RADES ${ }^{1}$ \\ ${ }^{1}$ Department of Radiation Oncology, University of Lübeck, Lübeck, Germany; \\ ${ }^{2}$ Medical Practice for Radiotherapy and Radiation Oncology, Hannover, Germany; \\ ${ }^{3}$ Department of Radiation Oncology, Mayo Clinic, Scottsdale, AZ, U.S.A.
}

\begin{abstract}
Background/Aim: Many patients with brain metastases receive whole-brain radiotherapy (WBRT). An important question is whether a delay between diagnosis of brain metastases and treatment impairs the patient's prognosis. Patients and Methods: This retrospective study investigated the impact of the interval between diagnosis of brain metastases and WBRT plus ten additional factors on overall survival (OS) in 573 patients. Prospective trials cannot be performed due to ethical concerns. Results: On univariate analyses, age $(p<0.001)$, performance status $(p<0.001)$, controlled primary tumor ( $p=0.047)$, metastases outside the brain $(p<0.001)$ and completion of WBRT $(p<0.001)$ were associated with OS. The interval between diagnosis and WBRT had no significant impact $(p=0.84)$. On multivariate analysis, age $(p=0.047)$, performance status $(p<0.001)$, metastases outside the brain $(p=0.029)$ and completion of WBRT $(p<0.001)$ maintained significance. Conclusion: WBRT may be postponed for good reasons (multidisciplinary coordination of treatment, missing histology). OS was significantly associated with previously identified factors, which demonstrates consistency of the present data.
\end{abstract}

Depending on the type of primary tumor, up to $30 \%$ of adult cancer patients develop brain metastases during the course of their malignant disease (1). The majority of these patients have already more than three metastases at their first presentation. This situation is often associated with a poor overall survival

\footnotetext{
*These Authors contributed equally to this work.

Correspondence to: Prof. Dirk Rades, MD, Department of Radiation Oncology, University of Lübeck, Lübeck, Ratzeburger Allee 160, 23562 Lübeck, Germany. Tel: +49 451 50045401, Fax: +49451 50045404, e-mail: rades.dirk@gmx.net
}

Key Words: Brain metastases, whole-brain radiotherapy, diagnostic imaging, time to treatment, overall survival.
(OS). Therefore, whole-brain radiotherapy (WBRT) alone is the most common treatment for this patient group. For patients with a very limited number of brain metastases, WBRT may be combined with a local treatment such as neurosurgical resection or stereotactic radiosurgery (SRS)/fractionated stereotactic radiotherapy (FSRT) (2). In patients with very few intracerebral lesions and a low risk of developing new brain metastases outside the treated lesions, SRS may be delivered without WBRT (3). However, many patients with poor performance status or significant co-morbidities and a few brain metastases receive WBRT alone because they would not tolerate neurosurgery or SRS (4). Generally, it is considered important that WBRT is started as soon as possible, because brain metastases often cause significant symptoms such as headache, nausea/vomiting and neurologic deficits $(5,6)$. Several issues may cause a delay of up to two or three weeks between the diagnosis of brain metastases and the start of WBRT, e.g. presentation and discussion of the case in a multidisciplinary tumor board, waiting for a definitive histology, treatment planning, and sometimes even limited capacities of linear accelerators. An important question is whether such a delay has a negative impact on the patient's prognosis. This question has not yet been evaluated. Therefore, we investigated the potential impact of the interval between diagnosis of brain metastasis and start of WBRT on OS. In order to reduce the risk of a selection bias due to the WBRT regimen, only patients assigned to longer-course WBRT (overall treatment time 2-4 weeks) and total doses of $30-40$ Gy were included. The study is retrospective in nature, because a prospective trial cannot be performed due to ethical concerns. It would be unacceptable to postpone WBRT only for study purposes, particularly in the case of symptomatic brain metastases.

\section{Patients and Methods}

In this retrospective study, 573 patients were included who had received longer-course WBRT alone between 2008 and 2017 for brain metastases, with 30 Gy in 10 fractions over 2 weeks $(\mathrm{N}=185)$, 35-37.5 Gy in $14-15$ fractions over 3 weeks $(\mathrm{N}=366)$ or $40 \mathrm{~Gy}$ in 
Table I. Overall survival (OS) rates following WBRT (univariate analyses).

\begin{tabular}{|c|c|c|c|c|c|}
\hline Factor & At 3 months (\%) & At 6 months $(\%)$ & At 9 months (\%) & At 12 months (\%) & $p$-Value \\
\hline \multicolumn{6}{|l|}{$\begin{array}{l}\text { Interval between diagnosis of } \\
\text { brain metastases and WBRT }\end{array}$} \\
\hline 0-7 days & 32 & 22 & 14 & 8 & \\
\hline 8-14 days & 36 & 20 & 14 & 9 & \\
\hline 15-21 days & 32 & 22 & 19 & 11 & 0.84 \\
\hline \multicolumn{6}{|l|}{ Gender } \\
\hline Female & 37 & 23 & 17 & 11 & \\
\hline Male & 31 & 20 & 14 & 7 & 0.098 \\
\hline \multicolumn{6}{|l|}{ Age } \\
\hline$\leq 65$ years & 38 & 26 & 20 & 11 & \\
\hline$\geq 66$ years & 29 & 17 & 10 & 7 & $<0.001$ \\
\hline \multicolumn{6}{|l|}{ ECOG-PS } \\
\hline $0-1$ & 44 & 31 & 23 & 14 & \\
\hline 2 & 28 & 15 & 10 & 5 & \\
\hline $3-4$ & 8 & 2 & 0 & 0 & $<0.001$ \\
\hline \multicolumn{6}{|l|}{ Primary tumor type } \\
\hline Breast cancer & 47 & 33 & 24 & 12 & \\
\hline Non-small cell lung cancer & 32 & 22 & 17 & 12 & \\
\hline Small cell lung cancer & 34 & 22 & 15 & 5 & \\
\hline Malignant melanoma & 28 & 17 & 11 & 11 & \\
\hline Colorectal cancer & 24 & 15 & 11 & 0 & \\
\hline Cancer of unknown primary & 18 & 12 & 6 & 0 & \\
\hline Other tumors & 33 & 15 & 7 & 5 & 0.055 \\
\hline \multicolumn{6}{|l|}{ Controlled primary tumor } \\
\hline No & 32 & 21 & 14 & 9 & \\
\hline Yes & 39 & 27 & 20 & 10 & 0.047 \\
\hline \multicolumn{6}{|l|}{ Number of brain metastases } \\
\hline $1-3$ & 34 & 24 & 19 & 11 & \\
\hline$\geq 4$ & 33 & 20 & 13 & 7 & 0.056 \\
\hline \multicolumn{6}{|l|}{ Type of imaging } \\
\hline Magnetic resonance imaging & 34 & 22 & 16 & 9 & \\
\hline Computed tomography & 31 & 21 & 12 & 8 & 0.25 \\
\hline \multicolumn{6}{|l|}{ Metastases outside the brain } \\
\hline No & 66 & 49 & 43 & 33 & \\
\hline Yes & 31 & 20 & 14 & 7 & $<0.001$ \\
\hline \multicolumn{6}{|l|}{ WBRT regimen } \\
\hline $30 \mathrm{~Gy}$ in 10 fractions & 30 & 17 & 11 & 8 & \\
\hline $35-37.5 \mathrm{~Gy}$ in $14-15$ fractions & 35 & 23 & 16 & 9 & \\
\hline 40 Gy in 20 fractions & 36 & 27 & 27 & 14 & 0.22 \\
\hline \multicolumn{6}{|l|}{ Completion of WBRT } \\
\hline No & 4 & 2 & 2 & 1 & \\
\hline Yes & 41 & 27 & 19 & 11 & $<0.001$ \\
\hline
\end{tabular}

WBRT: Whole-brain radiotherapy; ECOG: Eastern Cooperative Oncology Group; bold values=significant $p$-values.

20 fractions over 4 weeks $(\mathrm{N}=22)$. The fractionation regimen did depend on institutional preferences and physicians' choices at certain periods of time. WBRT was performed after computedtomography (CT)-based treatment planning with $6 \mathrm{MV}$-photon beams from a modern linear accelerator. Patients had an integrated head mask to maintain a stable position and reproducibility of the radiotherapy during each treatment.

The diagnosis of cerebral metastases was confirmed by magnetic resonance imaging (MRI) $(\mathrm{N}=390)$ or $\mathrm{CT}(\mathrm{N}=183)$. The major goal of this study was to investigate whether the time interval between the diagnosis of brain metastasis on MRI or CT and the start of
WBRT had an impact on the patients' overall survival (OS). In addition to the time interval (0-7 vs. 8-14 vs. 15-21 days), ten other factors were evaluated for potential associations with OS, including gender, age ( $\leq 65 v s . \geq 66$ years, median=66 years), Eastern Cooperative Oncology Group performance score (ECOG-PS) (0-1 vs. 2 vs. 3-4), type of primary tumor (breast cancer $v s$. non-small cell lung cancer (NSCLC) vs. small cell lung cancer (SCLC) vs. malignant melanoma $v s$. colorectal cancer $v s$. cancer of unknown primary (CUP) $v s$. other tumors), controlled primary tumor (no $v s$. yes), number of brain metastases (1-2 vs. $\geq 4)$, type of diagnostic imaging for brain metastases (MRI $v s$. CT), presence of metastases 
outside the brain (no vs. yes), dose-fractionation regimen of WBRT (30 Gy in 10 fractions vs. 35-37.5 Gy in 14-15 fractions $v s .40$ Gy in 20 fractions), and completion of the planned WBRT (no vs. yes). The distribution of these ten factors in the three groups regarding the interval between diagnosis of brain metastasis and WBRT is shown in Table I. The comparisons between the three groups were performed with the Chi-square test.

Time to death was counted from the last day of WBRT. The univariate analyses of OS were performed with the Kaplan-Meier method, and the differences between the Kaplan-Meier curves were assessed using the log-rank test (7). Those factors found to be significant on univariate analyses $(p<0.05)$ were subsequently included in a multivariate analysis (Cox proportional hazards model) to investigate whether these factors were independently associated with OS.

\section{Results}

For the entire cohort, the OS rates at 3,6,9 and 12 months following WBRT were $33 \%, 22 \%, 15 \%$ and $9 \%$, respectively. The median OS time from the end of radiotherapy was 2 months. On univariate analyses, younger age $(p<0.001)$, better ECOG-PS $(p<0.001)$, a controlled primary tumor $(p=0.047)$, absence of metastases outside the brain $(p<0.001)$ and completion of the WBRT as planned $(p<0.001)$ were significantly associated with improved OS. In addition, breast cancer $(p=0.055)$ and $1-3$ brain metastases $(p=0.056)$ showed a very strong trend. The time interval between diagnosis of brain metastasis on MRI or CT and start of WBRT had no significant impact on OS ( $p=0.84$, Figure 1$)$. The results of the entire univariate analyses are summarized in Table II.

On multivariate analysis, age (Cox Proportional Hazards Model) hazard ratio $[\mathrm{HR}]=1.24 ; 95 \%$ confidence interval $[\mathrm{CI}]=1.00-1.53 ; p=0.047)$, ECOG-PS (HR=1.33; 95\%CI=1.12$1.56 ; p<0.001)$, metastases outside the brain $(\mathrm{HR}=1.49$; 95\% CI $=1.06-2.17 ; p=0.029)$ and completion of the WBRT as planned $(\mathrm{HR}=3.56 ; 95 \% \mathrm{CI}=2.62-4.81 ; p<0.001)$ maintained their significant association with OS. The control of the primary tumor did not achieve significance $(\mathrm{HR}=1.24 ; 95 \% \mathrm{CI}=0.98$ $1.58 ; p=0.081)$.

\section{Discussion}

Many patients with brain metastases have a very poor OS (1, $2,8,9)$. In order to improve the prognoses of these patients, personalized treatment approaches have become more popular during recent years also for this group. Personalization of treatment is generally based on decisions made by multidisciplinary tumor boards often including radiation oncologists, medical oncologists, neurosurgeons, radiologists and pathologists. In cases of a single lesion, it can be difficult for the radiologist to distinguish between metastasis and a primary brain tumor, and additional procedures may be helpful. Furthermore, histology is important if no previous malignancy is known. These

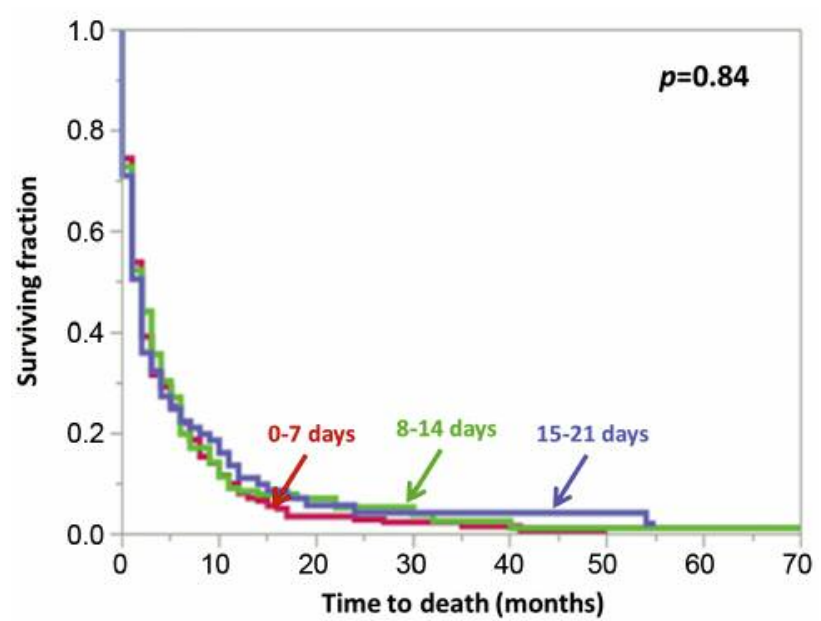

Figure 1. Comparison of the three time intervals between diagnosis of brain metastasis on MRI or CT and start of WBRT ((0-7 vs. 8-14 vs. 15 21 days) with respect to $O S$ (univariate analysis).

procedures may cause a delay regarding the beginning of the treatment. If a patient is selected to receive radiotherapy, this could be WBRT, SRS/FSRT or a combination of both modalities. However, SRS/FSRT is generally limited to very few (up to 3-5) brain metastases $(2,10)$. The majority of patients presenting with brain metastases have more than 35 lesions and receive WBRT alone. Regarding treatment, the question arises whether a delay in the start of WBRT has a negative impact on the patient's prognosis. The present study aimed to answer this question in a cohort of 573 patients treated with longer-course WBRT alone. According to its results, the interval between first diagnosis of brain metastases on MRI or CT and the start of WBRT had no significant impact on OS up to 12 months following WBRT.

In contrast to the interval between diagnosis of brain metastases and WBRT, several other factors were significantly associated with OS on multivariate analysis, including age, ECOG-PS, metastases outside the brain, and completion of the WBRT as planned. In addition, control of the primary tumor showed a trend to increase OS. Most of these factors have been previously identified by other studies performed to create predictive tools for estimating $\mathrm{OS}$ in patients irradiated for brain metastases. The first and most common of such tools, the recursive partitioning analysis (RPA) classification, was published in 1997 and based on the data from 1,200 patients of three randomized trials who had received WBRT (11). This tool included three prognostic groups (RPA classes I, II and III) with median OS times of 7.1 months, 4.2 months and 2.3 months. The three classes were designed based on four independent prognostic factors for OS, including Karnofsky performance score, age, metastases outside the brain, and control of the 
Table II. Distribution of the investigated factors in the three groups regarding the interval between the diagnosis of brain metastases until the start of WBRT.

\begin{tabular}{|c|c|c|c|c|}
\hline Factor & $\begin{array}{c}0-7 \text { days } \\
\mathrm{N} \text { patients }(\%)\end{array}$ & $\begin{array}{c}\text { 8-14 days } \\
\mathrm{N} \text { patients }(\%)\end{array}$ & $\begin{array}{c}15-21 \text { days } \\
\text { N patients }(\%)\end{array}$ & $p$-Value \\
\hline \multicolumn{5}{|l|}{ Gender } \\
\hline Female $(\mathrm{N}=245)$ & $123(42)$ & $89(46)$ & $33(40)$ & \\
\hline Male $(\mathrm{N}=328)$ & $172(58)$ & $106(54)$ & $50(60)$ & 0.95 \\
\hline \multicolumn{5}{|l|}{ Age } \\
\hline$\leq 65$ years $(N=272)$ & $148(50)$ & $92(47)$ & $32(39)$ & \\
\hline$\geq 66$ years $(\mathrm{N}=301)$ & $147(50)$ & $103(53)$ & $51(61)$ & 0.62 \\
\hline \multicolumn{5}{|l|}{ ECOG-PS } \\
\hline $0-1(\mathrm{~N}=304)$ & $157(53)$ & $113(58)$ & $34(41)$ & \\
\hline $2(\mathrm{~N}=182)$ & $94(32)$ & $56(29)$ & $32(39)$ & \\
\hline $3-4(\mathrm{~N}=87)$ & $44(15)$ & $26(13)$ & $17(20)$ & 0.55 \\
\hline \multicolumn{5}{|l|}{ Primary tumor type } \\
\hline Breast cancer $(\mathrm{N}=57)$ & $34(12)$ & $19(10)$ & $4(5)$ & \\
\hline Non-small cell lung cancer $(\mathrm{N}=282)$ & $127(43)$ & $106(54)$ & $49(59)$ & \\
\hline Small cell lung cancer $(\mathrm{N}=105)$ & $54(18)$ & $36(18)$ & $15(18)$ & \\
\hline Malignant melanoma $(\mathrm{N}=18)$ & $8(3)$ & $5(3)$ & $5(6)$ & \\
\hline Colorectal cancer $(\mathrm{N}=33)$ & $24(8)$ & $7(4)$ & $2(2)$ & \\
\hline Cancer of unknown primary $(\mathrm{N}=17)$ & $8(3)$ & $7(4)$ & $2(2)$ & \\
\hline Other tumors $(\mathrm{N}=61)$ & $40(14)$ & $15(8)$ & $6(7)$ & 0.14 \\
\hline \multicolumn{5}{|l|}{ Controlled primary tumor } \\
\hline No $(\mathrm{N}=317)$ & $156(53)$ & $111(57)$ & $50(60)$ & \\
\hline Yes $(\mathrm{N}=114)$ & $61(21)$ & $39(20)$ & $14(17)$ & \\
\hline Unknown $(\mathrm{N}=142)$ & $78(26)$ & $45(23)$ & $19(23)$ & 0.98 \\
\hline \multicolumn{5}{|l|}{ Number of brain metastases } \\
\hline $1-3(\mathrm{~N}=202)$ & $92(31)$ & $70(36)$ & $40(48)$ & \\
\hline$\geq 4(\mathrm{~N}=371)$ & $203(69)$ & $125(64)$ & $43(52)$ & 0.14 \\
\hline \multicolumn{5}{|l|}{ Type of imaging } \\
\hline Magnetic resonance imaging $(\mathrm{N}=390)$ & $195(66)$ & $139(71)$ & $56(67)$ & \\
\hline Computed tomography $(\mathrm{N}=183)$ & $100(34)$ & $56(29)$ & $27(33)$ & 0.92 \\
\hline \multicolumn{5}{|l|}{ Metastases outside the brain } \\
\hline No $(\mathrm{N}=50)$ & $17(6)$ & $23(12)$ & $10(12)$ & \\
\hline Yes $(N=464)$ & $255(86)$ & $145(74)$ & $64(77)$ & \\
\hline Unknown $(\mathrm{N}=59)$ & $23(8)$ & $27(14)$ & $9(11)$ & 0.13 \\
\hline \multicolumn{5}{|l|}{ WBRT regimen } \\
\hline 30 Gy in 10 fractions $(\mathrm{N}=185)$ & $89(30)$ & $67(34)$ & $29(35)$ & \\
\hline $35-37.5 \mathrm{~Gy}$ in $14-15$ fractions $(\mathrm{N}=366)$ & $197(67)$ & $119(61)$ & $50(60)$ & \\
\hline 40 Gy in 20 fractions $(\mathrm{N}=22)$ & $9(3)$ & $9(5)$ & $4(5)$ & 0.96 \\
\hline \multicolumn{5}{|l|}{ Completion of WBRT } \\
\hline No $(\mathrm{N}=125)$ & $69(23)$ & $36(18)$ & $20(24)$ & \\
\hline Yes $(\mathrm{N}=448)$ & $226(77)$ & $159(82)$ & $63(76)$ & 0.86 \\
\hline
\end{tabular}

WBRT: Whole-brain radiotherapy; ECOG: Eastern Cooperative Oncology Group.

primary tumor. Another very commonly used tool is the graded prognostic assessment (GPA) score published in 2008 (12). This prognostic instrument was created based on the data of patients from five randomized trials who received WBRT, which was supplemented by an SRS boost in one arm of a trial. The GPA score included four prognostic groups with median OS times of 2.6, 3.8, 6.9 and 11.0 months, respectively, and was based on Karnofsky performance score, age, metastases outside the brain and number of brain metastases (12). In the present study, the number of brain metastases did not achieve significance on univariate analysis but showed a trend for an association with OS $(p=0.056)$. An independent predictor of OS that was not previously described for WBRT of brain metastases is completion of the WBRT as planned. In the present study, this factor was highly significant $(p<0.001)$. The reason for non-completion of WBRT mostly is a decline in the patient's performance status due to progression of the malignant disease or to other complications such as pneumonia or pulmonary embolism leading to an early death. Only $4 \%$ of these patients survived 3 months or longer following WBRT. 
The comparably poor OS in our study may reflect the current trend to avoid WBRT whenever reasonably possible, particularly in patients with few brain metastases and a favorable OS prognosis, and to use SRS/FSRT alone instead. Two randomized trials have demonstrated that the addition of WBRT to SRS/FSRT leads to a significantly more pronounced decline in neurocognitive function than SRS/FSRT alone (13, 14). In the trial of Chang et al., the rates of neuro-cognitive deficits (compared to baseline) at 4 months following irradiation were $96 \%$ with and $24 \%$ without WBRT $(p<0.001)$ (13). In the Alliance trial, the corresponding rates at 3 months were $92 \%$ and $64 \%$, respectively $(p<0.001)(14)$. Another trial from Japan suggested that using SRS/FSRT alone without WBRT was reasonable for up to 10 metastases $(15,16)$. The authors found no significant difference between patients with 2-4 lesions and those with 5-10 lesions with respect to median OS (10.8 vs. 10.8 months), grade 3-4 adverse events (2\% vs. $3 \%)$ and neuro-cognitive decline after 4 years (14\% vs. $11 \%)$. However, despite the data that led to a decrease in the proportion of patients with brain metastases receiving WBRT alone, many patients, particularly patients with multiple brain metastases and/or a poor performance status, will continue to be candidates for WBRT alone. When WBRT is used, modern approaches such as hippocampal sparing and concurrent treatment with memantine should be considered to reduce the risk of treatment-related neuro-cognitive deficits $(17,18)$.

In the present study, the time interval between diagnosis of brain metastasis using MRI or CT and start of WBRT had no impact on OS. Thus, if difficult treatment decisions require multidisciplinary coordination, or waiting for a definitive histology is important prior to the start of treatment, WBRT may be postponed for some days. However, since brain metastases are often associated with significant clinical symptoms, WBRT should be started as soon as reasonably possible. Corticosteroids can be used to help with symptoms as well. In contrast to the interval between diagnosis of brain metastasis and WBRT, OS was significantly associated with the pre-treatment factors age, performance status and metastases outside the brain. These factors have been previously identified as independent predictors of OS in patients irradiated for brain metastases, which demonstrates consistency of the data of the present study with the literature and supports validity of the results.

\section{Conflicts of Interest}

On behalf of all Authors, the corresponding Author states that there is no conflict of interest related to this study.

\section{References}

1 Khuntia D, Brown P, Li J and Mehta MP: Whole-brain radiotherapy in the management of brain metastasis. J Clin Oncol 24: 1295-1304, 2006.
2 Tsao MN, Rades D, Wirth A, Lo SS, Danielson BL, Gaspar LE, Sperduto PW, Vogelbaum MA, Radawski JD, Wang JZ, Gillin MT, Mohideen N, Hahn CA and Chang EL: Radiotherapeutic and surgical management for newly diagnosed brain metastasis(es): An American Society for Radiation Oncology evidence-based guideline. Pract Radiat Oncol 2: 210-225, 2012.

3 Huttenlocher S, Dziggel L, Hornung D, Blanck O, Schild SE and Rades D: A new prognostic instrument to predict the probability of developing new cerebral metastases after radiosurgery alone. Radiat Oncol 9: 215, 2014.

4 Rades D, Janssen S, Dziggel L, Blanck O, Bajrovic A, Veninga $\mathrm{T}$ and Schild SE: A matched-pair study comparing whole-brain irradiation alone to radiosurgery or fractionated stereotactic radiotherapy alone in patients irradiated for up to three brain metastases. BMC Cancer 17: 30, 2017.

5 Wong J, Hird A, Zhang L, Tsao M, Sinclair E, Barnes E, Danjoux $C$ and Chow E: Symptoms and quality of life in cancer patients with brain metastases following palliative radiotherapy. Int J Radiat Oncol Biol Phys 75: 1125-1131, 2009.

6 van Oorschot B, Beckmann G, Schulze W, Rades D and Feyer P: Radiotherapeutic options for symptom control in breast cancer. Breast Care (Basel) 6: 14-19, 2011.

7 Kaplan EL and Meier P: Non-parametric estimation from incomplete observations. J Am Stat Assoc 53: 457-481, 1958.

8 Dziggel L, Schild SE, Veninga T, Bajrovic A and Rades D: Clinical factors asssociated with treatment outcomes following whole-brain irradiation in patients with prostate cancer. In Vivo 31: 35-38, 2017.

9 Sehmisch L, Schild SE and Rades D: Development of a survival score for patients with cerebral metastases from melanoma. Anticancer Res 37: 249-252, 2017.

10 Dziggel L, Bajrovic A, Schild SE and Rades D: Stereotactic radiosurgery alone for one to two brain metastases from cancer of unknown primary. Anticancer Res 38: 565-567, 2018.

11 Gaspar L, Scott C, Rotman M, Asbell S, Phillips T, Wasserman T, McKenna WG and Byhardt R: Recursive partitioning analysis (RPA) of prognostic factors in three Radiation Therapy Oncology Group (RTOG) brain metastases trials. Int J Radiat Oncol Biol Phys 37: 745-751, 1997.

12 Sperduto PW, Berkey B, Gaspar LE, Mehta M and Curran W: A new prognostic index and comparison to three other indices for patients with brain metastases: an analysis of 1,960 patients in the RTOG database. Int J Radiat Oncol Biol Phys 70: 510-514, 2008.

13 Chang EL, Wefel JS, Hess KR, Allen PK, Lang FF, Kornguth DG, Arbuckle RB, Swint JM, Shiu AS, Maor MH and Meyers CA: Neurocognition in patients with brain metastases treated with radiosurgery or radiosurgery plus whole-brain irradiation: a randomised controlled trial. Lancet Oncol 10: 1037-1044, 2009.

14 Brown PD, Jaeckle K, Ballman KV, Farace E, Cerhan JH, Anderson SK, Carrero XW, Barker FG 2nd, Deming R, Burri SH, Ménard C, Chung C, Stieber VW, Pollock BE, Galanis E, Buckner JC and Asher AL: Effect of radiosurgery alone vs radiosurgery with whole brain radiation therapy on cognitive function in patients with 1 to 3 brain metastases: A randomized clinical trial. JAMA 316: 401-409, 2016.

15 Yamamoto M, Serizawa T, Shuto T, Akabane A, Higuchi Y, Kawagishi J, Yamanaka K, Sato Y, Jokura H, Yomo S, Nagano O, Kenai H, Moriki A, Suzuki S, Kida Y, Iwai Y, Hayashi M, 
Onishi H, Gondo M, Sato M, Akimitsu T, Kubo K, Kikuchi Y, Shibasaki T, Goto T, Takanashi M, Mori Y, Takakura K, Saeki N, Kunieda E, Aoyama H, Momoshima S and Tsuchiya K: Stereotactic radiosurgery for patients with multiple brain metastases (JLGK0901): a multi-institutional prospective observational study. Lancet Oncol 15: 387-395, 2014.

16 Yamamoto M, Serizawa T, Higuchi Y, Sato Y, Kawagishi J, Yamanaka K, Shuto T, Akabane A, Jokura H, Yomo S, Nagano O and Aoyama $\mathrm{H}$ : A Multi-institutional prospective observational study of stereotactic radiosurgery for patients with multiple brain metastases (JLGK0901 study update): Irradiation-related complications and long-term maintenance of mini-mental state examination scores. Int J Radiat Oncol Biol Phys 99: 31-40, 2017.

17 Gondi V, Pugh SL, Tome WA, Caine C, Corn B, Kanner A, Rowley H, Kundapur V, DeNittis A, Greenspoon JN, Konski AA, Bauman GS, Shah S, Shi W, Wendland M, Kachnic L and Mehta MP: Preservation of memory with conformal avoidance of the hippocampal neural stem-cell compartment during wholebrain radiotherapy for brain metastases (RTOG 0933): a phase II multi-institutional trial. J Clin Oncol 32: 3810-3816, 2014.
18 Brown PD, Pugh S, Laack NN, Wefel JS, Khuntia D, Meyers C, Choucair A, Fox S, Suh JH, Roberge D, Kavadi V, Bentzen SM, Mehta MP and Watkins-Bruner D; Radiation Therapy Oncology Group (RTOG): Memantine for the prevention of cognitive dysfunction in patients receiving whole-brain radiotherapy: a randomized, double-blind, placebo-controlled trial. Neuro Oncol 15: 1429-1437, 2013.
Received October 19, 2018

Revised October 29, 2018

Accepted October 30, 2018 